\title{
Histological and radiological study of calcified placenta
}

\author{
Pushpa Goswami ${ }^{1}$, Samreen memon ${ }^{2}$, Kussum Pardeep ${ }^{3}$ \\ ${ }^{I}$ Assistant Professor, Department of Anatomy Liaquat University of Medical and Health sciences Jamshoro, \\ Pakistan \\ ${ }^{2}$ Assistant Professor and HOD of Anatomy department Liaquat University of Medical and Health sciences, \\ Pakistan \\ ${ }^{3}$ Associate professor of radiology Liaquat University hospital Pakistan
}

\begin{abstract}
Normal foetal growth and survival depends on proper development and function of the placenta. It serves to maintain a maternal-foetal interference for the exchange of blood gases, nutrients, and waste. The placenta has been described as a "diary of intrauterine life" and it may elucidate many aspects of intra uterine life. The aim of this study is to observe the histological and radiological changes in excessive placental calcification, in pregnancy induced hypertension $(P I H)$ and placental abruption. This retrospective study was conducted at the department of Anatomy of Liaquat University of Medical \& Health Sciences Jamshoro. One hundred twenty placentae were collected from labour room and gynaecology operation theatre of Liaquat University Hospital. Forty placentae from parturient suffered from PIH, forty from parturient with placental abruption \& forty placentae from parturient of normal pregnancy (Control Group). Age of all parturient is between 17 to 32 years. Radiological study was conducted in the department of radiology of Liaquat University Hospital Jamshoro. Approximately five mm pieces of placenta was taken and processed for histological study. Both radiology and histological studies show highly significant $(p=<0.001)$ difference in calcification in placental abruption and PIH group as compared to control.
\end{abstract}

Key words: calcification, Placenta, PIH, placental abruption.

\section{Introduction}

The placenta is a dynamic organ which is unique in its development and functions. It is the only organ in the body which is derived from two separate individuals, the mother and the foetus. It is vital for respiratory, nutritional, excretory, endocrinal and immunological functions of the foetus.

A systematic examination of placenta is often ignored by the physician, gynaecologist, paediatrician and pathologist in spite of its very useful role in the foetal development. [1,2]

Calcification is common in human placentae and recognized as a normal feature of maturation and aging of this organ. It is seen that more than $50 \%$ of placentae have some degree of calcification and $18 \%$ of placentae show excessive calcification. Increased calcification of placenta has four times more serious negative consequences like foetal growth restriction and foetal distress than in the uncalcified group. Early preterm placental calcification is associated with a higher incidence of poor foetal outcomes, thus may serve as a diagnostic marker. $[3,4]$

During pregnancy minor placental calcification tend to be found at late stages of gestation due to tissue aging. However there are certain medical conditions in mother which leads to excessive placental calcification such as Pregnancy induced hypertension (PIH), Placental abruption, intra uterine growth restriction (IUGR), cigarette smoking. These complications of pregnancy are reflected in the placenta. [5]

In normal pregnancies, placental separation occurs soon after birth, while in pregnancies complicated by abruption, the placenta begins to detach before birth and causes bleeding from the genital tract known as ante partum haemorrhage (APH). Pregnancy-induced hypertension ( $\mathrm{PIH})$ is defined as hypertension during pregnancy when associated with new-onset proteinuria. Both conditions are major cause of perinatal mortality and maternal morbidity in the developing countries like Pakistan. The aetiology of both conditions remains unknown. It is supposed to result from abnormal trophoblast invasion leading to rupture of the spiral arteries and premature separation of the placenta followed by death of placental tissue, and so forth accumulation of calcium in abruption. While in PIH abnormal trophoblast invasion of maternal spiral arteries which fails to dilates and results in decreased uteroplacental perfusion causing placental dysfunction resulting in foetal growth restriction, reduced foetal length, and preterm delivery. $[6,7,8]$ This study was aimed to detect the histological and radiological changes in highly calcified placenta from APH and PIH.

\section{Material And Methods}

This case control study was conducted at the department of Anatomy of Liaquat University of Medical \& Health Sciences Jamshoro Sindh Pakistan. Hundred and twenty placentae were collected from 
labour room and gynaecology operation theatre of Liaquat University Hospital. Forty placentae from parturient that had pregnancy induced hypertension \& forty placentae from parturient with history of Abruption of placenta \& forty cases belonged to normal pregnancy (Control Group). Age of all mothers was between 17 to 32 years. The data was collected on the prescribed proforma. Placenta was washed in running tap water, tagged with code numbers and were preserved in $10 \%$ formalin solution for 48 hours for fixation.

\subsection{Study of placental calcification on Histology}

Placenta was cut along the maximum diameter into two halves. Approximately one $\mathrm{cm}$ piece of placenta was cut from one half and were processed for routine paraffin embedment. Sections were cut by automatic microtome and mounted on clean gelatinized slides, stained with H\&E and von kossa special stain for calcium. Areas of placental calcifications were counted with the help of microscope and photo micrographs were taken. Same procedure is also followed by the authors in their previous study and found them very helpful. $[9,10]$

\subsection{Study of placenta on radiography:}

Radiographic study of calcified placenta was performed on Allangior 500 MA machine with fuji films in department of radiology LUH. The placentae lay out with flat maternal surface downward in plastic tray which was placed on the $\mathrm{x}$-ray plate. The exposure factors were as follows: 0.2 seconds; $50 \mathrm{~mm}$ fine focus using $50 \mathrm{kV}$ and a tube film distance of 40 inches. Radiographs were labelled according to corresponding code numbers. Assessment of placental calcification on radiology was done with the help of associate professor of radiology.

The placentae were graded according to the number of foci of calcification as shown under:

Grade $0 \ldots \ldots \ldots . . .$. No calcification.

Grade 1............Slight (two foci of calcification present)/ field

Grade 2................ Moderate (3-6 foci of calcification present)/ field

Grade 3..............Severe (more than 6 foci of calcification present or diffuse)/ field [11]

\section{Results}

Calcification on histology and radiology were studied, number of calcification recorded in specially designed data sheets and analysed. Demographic data regarding parity and maternal age is shown in Table 1 \& Table 2, Figure 1. In control group in age group 17-20 years show 10 case (25\%), 21-24 years 07 cases (17.5\%), and 25-28 years 15 cases (37\%) 29-32 years 08 cases (20\%). In Abruptio placentae age group 17-20 years show no case, $21-24$ years 06 cases (15\%), 25-28 years 12 cases (30\%) 29-32 years 22 cases (55\%). In PIH in age group 17-20 years $04(10 \%)$ cases, $21-24$ years 12 cases (30\%),25-28 years 16 cases (40\%),29-32 years 08 cases (20\%).Peak reproductive age (17-32) years is taken and divided into four groups.

On histology the placentae from PIH (fig. ) and abruption placentae (fig.) showed more calcific spots as compared to control (fig 2,3) in table 3.

On radiology the placentae from PIH (fig.9, 10) and abruption placentae (fig.11, 12) showed more calcific spots as compared to control (fig.8) in table 4.

Table-1 is showing parity

\begin{tabular}{|l|l|l|l|}
\hline \multirow{2}{*}{ PARITY } & \multicolumn{3}{|c|}{ NO.OF CASES } \\
\cline { 2 - 4 } & Control & $\begin{array}{c}\text { Placental } \\
\text { abruption }\end{array}$ & PIH \\
\hline PO (primi) & $25(62 \%)$ & $04(10 \%)$ & $20(50 \%)$ \\
\hline P1 \&P2 & $07(18 \%)$ & $10(25 \%)$ & $12(30 \%)$ \\
\hline P3-P7 & $08(20 \%)$ & $26(65 \%)$ & $08(20 \%)$ \\
\hline
\end{tabular}

Table-2 showing age groups

\begin{tabular}{|l|l|l|l|}
\hline \multirow{2}{*}{ AGE GROUPS } & \multicolumn{3}{|c|}{ NO. OF CASES } \\
\cline { 2 - 4 } & CONTROL & Abruptio placentae & PIH \\
\hline $17-20$ years & $10(25 \%)$, & $00(00 \%)$, & $04(10 \%)$, \\
\hline $21-24$ years & $07(17.5 \%)$, & $06(15 \%)$, & $12(30 \%)$, \\
\hline $25-28$ years & $15(37.5 \%)$, & $12(30 \%)$, & $16(40 \%)$, \\
\hline $29-32$ years & $08(20 \%)$, & $22(55 \%)$, & $08(20 \%)$, \\
\hline
\end{tabular}




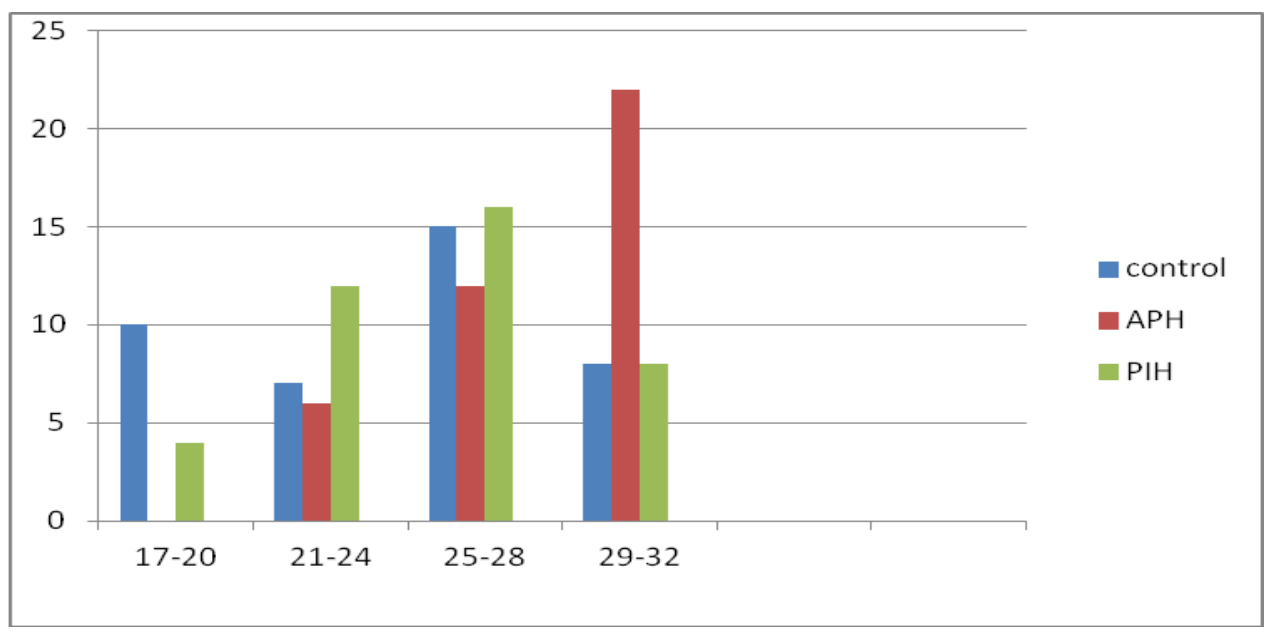

Figure 1: showing age groups

Table-3 shows number of calcified areas per low power field (x10) on microscopy.

\begin{tabular}{|c|c|c|c|c|c|c|}
\hline & $\begin{array}{c}\text { Minimum } \\
\text { areas of } \\
\text { calcification }\end{array}$ & $\begin{array}{c}\text { Maximum } \\
\text { Areas of } \\
\text { calcification }\end{array}$ & Mean & $\begin{array}{l}\text { Std. } \\
\text { Error } \\
\text { mean }\end{array}$ & $\begin{array}{c}\text { std. } \\
\text { Deviation }\end{array}$ & $\mathrm{P}$ value \\
\hline control & 1 & 5 & 2.93 & .210 & 1.328 & \\
\hline $\begin{array}{l}\text { Abruptio } \\
\text { placentae }\end{array}$ & 6 & 22 & 13.00 & .768 & 4.857 & $<.0001$ \\
\hline $\mathrm{PIH}$ & 10 & 20 & 14.97 & .445 & 2.815 & $<.0001$ \\
\hline
\end{tabular}
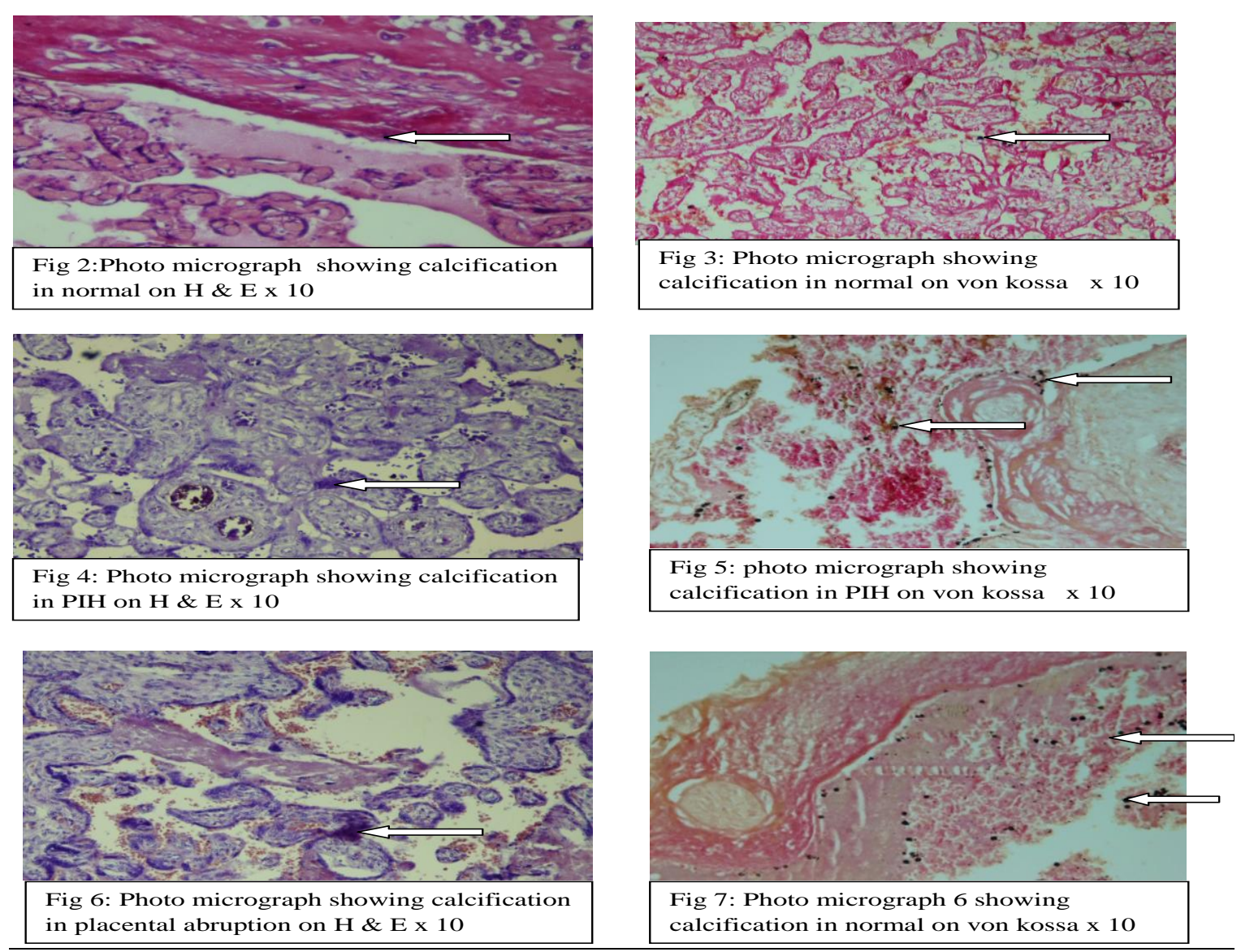
Table-4 shows radiological grading of placental calcification

\begin{tabular}{|c|c|c|c|}
\hline $\begin{array}{c}\text { Grades of } \\
\text { calcification }\end{array}$ & Control & $\begin{array}{c}\text { Abruptio } \\
\text { placentae }\end{array}$ & PIH \\
\hline 0 & 25 & 00 & 00 \\
\hline 1 & 13 & 00 & 00 \\
\hline 2 & 02 & 15 & 10 \\
\hline 3 & 00 & 25 & 30 \\
\hline Mean & 0.42 & 2.75 & 2.62 \\
\hline SEM & 0.094 & 0.069 & 0.78 \\
\hline p value & & $<0.0001$ & $<0.0001$ \\
\hline
\end{tabular}

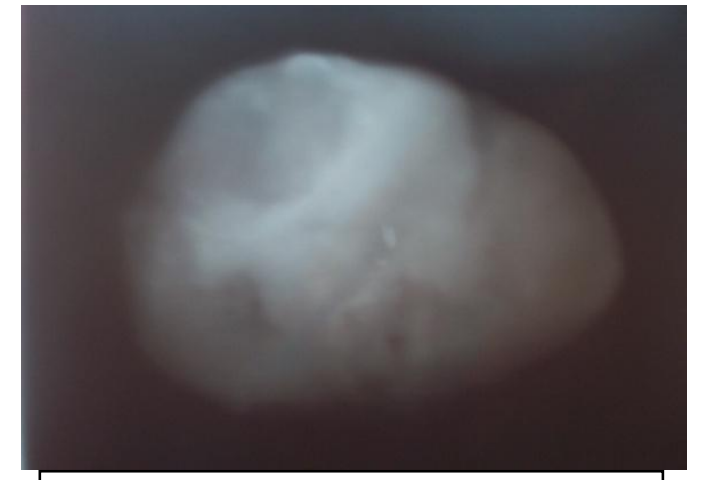

Fig 8: Radiograph of normal placenta

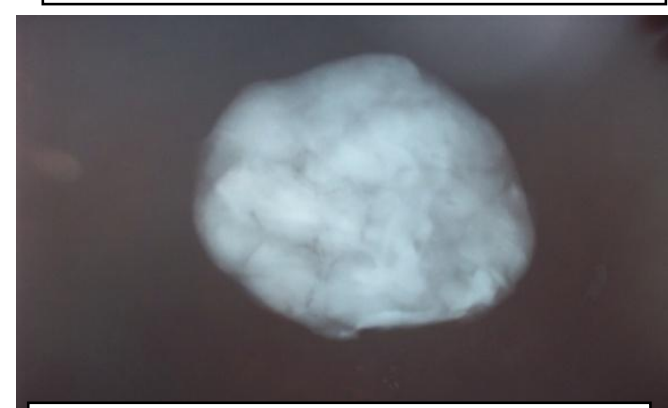

Fig 10: Radiograph of placenta of PIH grade 3

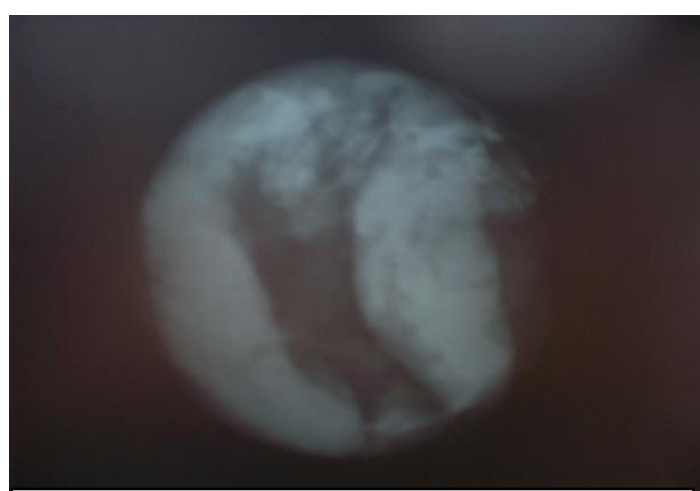

Fig 12: Radiograph of placenta showing abruption of grade 3

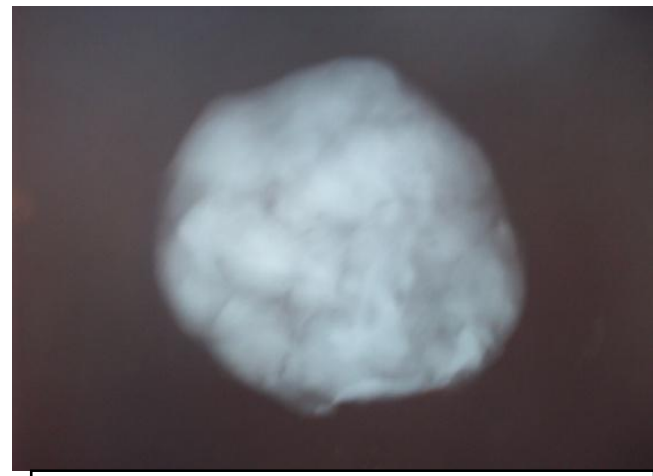

Fig 9: Radiograph of PIH grade 2

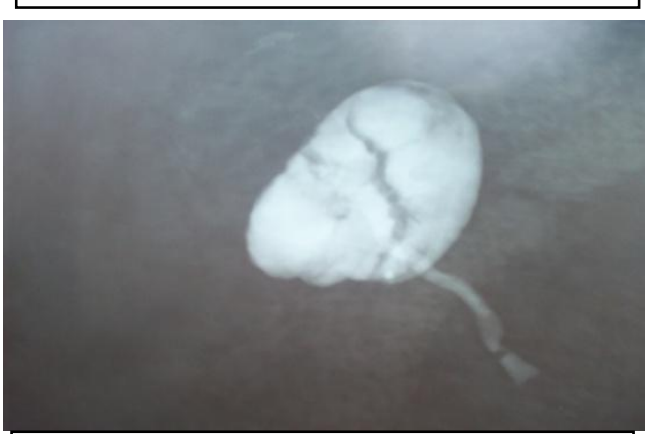

Fig: 11 Radiograph of placenta showing abruption of grade 2

\section{Discussion}

The foetus, placenta and mother form a composite triad of dynamic equilibrium, and dysfunction of any one of them can affect the others. Calcification is common in human placentae and recognized as normal part of maturation and aging of this organ. The pathological maturation of placenta because of 
excess calcification can lead to fetal growth restriction which is the second most common cause of perinatal death after prematurity. [3]

Early preterm placental calcification is associated with a higher incidence of poor pregnancy outcome, both in mother (postpartum haemorrhage, maternal transfer to the intensive care unit) and foetus (including preterm birth low birth weight, low Apgar score and neonatal death). [12] This prospective study is based on histological and radiological examination of 120 placentae for excessive placental calcification due to PIH and placental abruption. Calcifications are mostly observed in the villi and basement membrane of the villi which is strongly suggestive of uteroplacental insufficiency because of narrow lumen. We see calcification from one millimeter to biggest one of about 5 millimeters.

Placental calcification was seen significantly more frequently in primigravidas as cited by Russel J G B, Fielden P same results were observed in this study. Similar results are cited by Spirit B A, Cohen W N,Weinstein H M. $[13,14]$

In PIH and APH mean number of calcified areas on gross as well as on microscopy seen were more than in normal placenta. In the study conducted by Majumandar S in Kolkkata and by Sarkar M in Mahattma Gandhi institute of medical science Sew gram India they have observed similar findings. $[15,16]$

Different results were cited by Narasimha A, in their studies found calcification more in control group then in PIH. [17]

The presence of preterm placental calcification is a predictor of poor uteroplacental flow and worse pregnancy outcome, need closer monitoring for maternal and fetal well being.

\section{Conclusion}

Finally placental calcification is a normal physiological process occurring in pregnancy but if this process is exaggerated than it become pathological and causes remarkable changes both macroscopic and microscopic. Excessive placental calcification causes uteroplacental insufficiency and compromises foetal circulation and growth. We unveiled one of the factor involved in uteroplacental insufficiency is deposition of excess calcium especially in villi, future research is needed to find out other factors and proper mechanism of calcium deposition at cellular level.

\section{References}

[1]. Ragunath G, Lakshmi v, shenoy VS. A study on the Morphology and the Morphometry of the Human Placenta and its Clinical Relevance in a population in Tamilnadu Journal of Clinical and Diagnostic Research. 2011 Apr, Vol-5(2):282-286

[2]. Devi C K, Neelam S, Raghupathy NS The Histological Findings in Human Placenta at Different Gestational Ages IOSR-JDMS $2013 ; 6(1): 29-31$

[3]. Sarkar M, Ingole IV, Ghosh SsK, Bhakta A, Das RS, Tandale S, Tarnekar AM. Calcification in Placenta. J Anat soc India 2007; 56(1):01-06.

[4]. Guo Y, Zhang D, Lu H, Luo S, ShenX. Association between calcifying nano particles and placental calcification Int J Nanomedicine. 2012; 7: 1679-1686.

[5]. Agababov RM, Abshina TN, Suzina NE, Vainshtein MB, Schartburd PM. Link between the early calcium deposition in placenta and nanobacterial like infection. J Biosic 2007; 32(6): 1163-68.

[6]. Elsasser DA, Ananth CV, Prasad V, Vintzileos AM. Diagnosis of Placental Abruption: Relationship between Clinical and Histopathological Findings Eur J Obstet Gynecol Reprod Biol. 2010 February; 148(2): 125.

[7]. Singh S, Gugapriya TS. Micro anatomical analysis of hypertensive placenta A retrospective case control study. National $\mathrm{j}$ of clinical anatomy 2013;2 (1) p 5-10

[8]. Rasmussen S, Irgens LM. Fetal growth and body proportion in Preeclampsia. Obstet Gynaecol 2003; 101(3):575-83.

[9]. Baloch AH, Memon SF, Ansari AK. Comparison of placentae from hypertension associated pregnancies and normal pregnancies. JLUMHS 2012; 11(01):03-06

[10]. Goswami P, Lata H, Memon S, Khaskhelli LB.Excessive Placental Calcification Observed in PIH Patients and its Relation to Fetal Outcome. JLUMHS 2012; 11: (3) p 144-14

[11]. Tindall VR, Scott JS. Placental calcification: A study of 3,025 singletons and multiple pregnancies .BJOG 1965; 72:356-373.

[12]. Chen KH, Chen LR, Lee YH. Exploring the relationship between preterm placental calcification and adverse maternal and fetal outcome. ultrasound Obstet Gynecol. $2011 ; 37(3): 328-34$

[13]. Russel J G B, Fielden P. The antenatal diagnosis of placental calcification Bjog 2005 ; ( 9): 813 - 816.

[14]. Spirit B.A, Cohen .N, Weinstein H. The incidence of placental calcification in normal pregnancy. Radiology 1982; 142:707-711.

[15]. Majumdar S, Dasgupta H, Bhattacharya K, Bhattacharya A. A Study of Placenta in Normal and Hypertensive Pregnancies.J Anat Soc India 2005; 54 (2): 1-9.

[16]. Sarkar M, Ingole IV, Ghosh SK, Bhakta A, Das RS, Tandale S, Tarnekar AM. Calcification in Placenta. J Anat soc India 2007; 56(1):01-06.

[17]. Narasimha A, Vasudeva D S. Spectrum of changes in placenta in toxemia of pregnancy. Indian J Pathol Microbiol 2011;54:15-20 